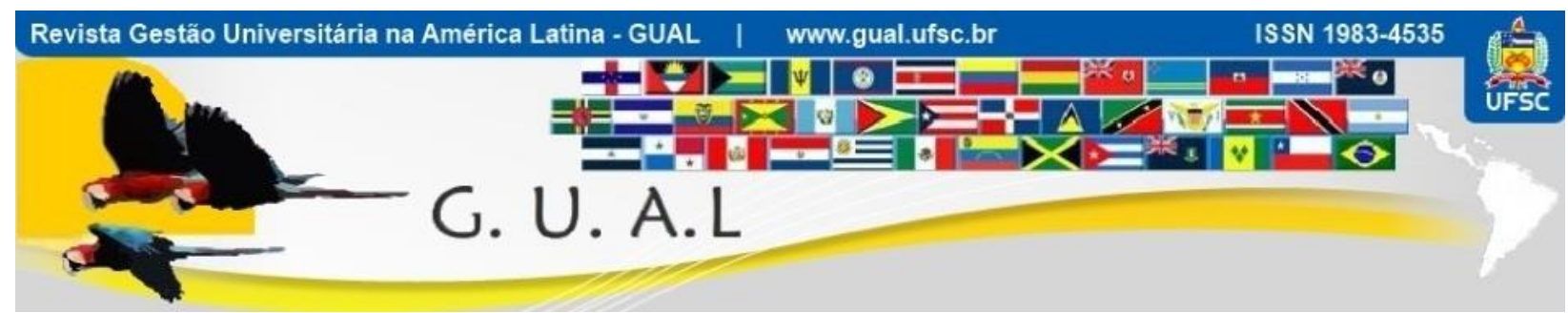

DOI: http://dx.doi.org/10.5007/1983-4535.2014v7n1p298

\title{
MESTRADOS PROFISSIONAIS EM ADMINISTRAÇÃO, CONTABILIDADE E TURISMO NO BRASIL E SEU PROCESSO DE AVALIAÇÃO
}

\section{PROFESSIONAL MASTERS IN BUSINESS ADMINISTRATION, ACCOUNTING AND TOURISM IN BRAZILAND ITS EVALUATION PROCESS}

Graziela Dias Alperstedt, Doutora Universidade do Estado de Santa Catarina - UDESC gradial@gmail.com

Sérgio Bulgacov, Doutor Fundação Getúlio Vargas - FGV

sergio.bulgacov@fgv.br

Filipe Ivo Pereira, Mestrando Universidade do Estado de Santa Catarina - UDESC filipeivopereira@ hotmail.com

Luciana Ribeiro do Valle, Graduanda Universidade do Estado de Santa Catarina - UDESC lucianaribeirov@gmail.com

Recebido em 17/setembro/2013

Aprovado em 11/dezembro/2013

Sistema de Avaliação: Double Blind Review

Esta obra está sob uma Licença Creative Commons Atribuição-Uso. 


\title{
RESUMO
}

Esse trabalho se propôs a analisar o atual sistema de avaliação da Capes para os cursos de mestrado profissional em Administração, Ciências Contábeis e Turismo no Brasil a partir dos próprios professores e coordenadores. $\mathrm{O}$ trabalho se alicerça nos fundamentos sobre os mestrados profissionais no Brasil e sobre o processo de avaliação. Os dados foram coletados por meio de um survey eletrônico aplicado junto aos gestores e aos professores dos cursos de mestrado profissional em administração, contabilidade e turismo no Brasil. $\mathrm{O}$ artigo apresenta os resultados da análise quantitativa realizada a partir da estatística descritiva e do cruzamento de dados e revela que, apesar das críticas e da necessidade de mudança, a comunidade acadêmica ainda não possui respostas e soluções para mudar a avaliação dos mestrados profissionais. O trabalho oferece reflexões e sugestões aos responsáveis pelo processo.

Palavras-chave: Avaliação da Pós-Graduação. Mestrados Profissionais. Capes.

\begin{abstract}
This study aimed to examine the current evaluation system of Capes for professional master's in Business Administration, Accounting and Tourism in Brazil from their own teachers and coordinators. The work is grounded in the literature of the professional master in Brazil and on the evaluation process. Data were collected through an electronic survey applied with the managers and teachers of Master Professional in management, accounting and tourism in Brazil. The article presents the results of quantitative analysis performed from the descriptive statistics and cross-checks and shows that, despite the criticism and the need for change, the academic community does not have answers and solutions to change the assessment of professional master. The paper offers reflections and suggestions to those responsible for the process.
\end{abstract}

Keywords: Evaluation of Graduate. Professional Masters. Capes. 


\section{INTRODUÇÃO}

Os mestrados profissionais no Brasil já vinham sendo objeto de análise desde a década de sessenta, quando o parecer no 977 CES de 1965 já fazia alusão a essa modalidade stricto sensu utilizando o exemplo das universidades norte americanas. Entretanto, esses cursos somente foram regulamentados pela Portaria 80 de novembro de 1998 da Capes (CAPES, 1998), após vários anos de debates sobre o assunto. Desde 2005 em um seminário realizado em São Paulo que reuniu representantes de várias áreas de conhecimento, debates vinham sendo travados no sentido de expor aspectos positivos da adoção, pela CAPES, de uma modalidade de mestrado distinto do acadêmico, mas que preservasse o mesmo rigor daquele. (RIBEIRO, 2005) Passados 15 anos de sua regulamentação, os mestrados profissionais ainda sofrem por sua falta de identidade e, porque não dizer, de certo preconceito por grande parte daqueles que se dedicam à pós-graduação brasileira.

Vários são os argumentos contrários a essa modalidade de mestrado, especificamente na área de administração. Um dos questionamentos diz respeito às diferenças entre os mestrados acadêmicos e os profissionais partindo do pressuposto de que a administração é por si só uma ciência social aplicada e, como tal, não haveria sentido em se ter uma modalidade de "administração teórica" em contraposição a um modalidade de "administração prática". (VASCONCELOS; VASCONCELOS, 2010) Outro conjunto de argumentos contrários ao mestrado profissional diz respeito ao risco de submeter a pesquisa aos ditames do capital e ao interesse de pequenos grupos (RIBEIRO, 2005).

Para muitos, e para a própria CAPES (CAPES, 2009b) uma das diferenças entre mestrados profissionais e acadêmicos reside na formação do mestrando. $O$ primeiro se destinaria à formação de um profissional, dedicando-se a um trabalho final que favoreça a solução de problemas reais, enquanto o segundo se destinaria à formação de pesquisadores e professores. Assim, haveria uma diferença do candidato ao mestrado. Na modalidade profissional, a grande maioria seria formada por profissionais.

Todavia, na prática as diferentes modalidades se confundem tendo em vista que o mestrado profissional também habilita para o magistério e, da mesma forma, dá acesso aos cursos de doutorado. O próprio documento de área da administração (CAPES, 2009a) chama a atenção para essa "crise de identidade" uma vez que muitas das dissertações desenvolvidas em mestrados acadêmicos são nitidamente "profissionais" ao passo que muitos trabalhos desenvolvidos nos mestrados profissionais são claramente "acadêmicos". 


\section{MESTRADOS PROFISSIONAIS EM ADMINISTRAÇÃO, CONTABILIDADE E TURISMO NO BRASIL E

Pressupondo que o status de um mestre profissional é igual ao de um mestre acadêmico e que o nível de exigência em termos de qualidade também deverá ser o mesmo, o aumento da crise de identidade se agrava em virtude de que o sistema de avaliação, bem como as fichas de avaliação, desde o início, eram compostos de critérios indistinguíveis entre as duas modalidades. (CAPES, 2009a) A questão fundamental reside na necessidade de que a avaliação seja distinta para ambas as modalidades de mestrado, conforme salientam Paixão e Becker (2012), assim como Castro (2005), Ribeiro (2005), Agopyan e Lobo (2007), Negret (2008), Fischer (2010a, 2010b) e Menandro (2010).

Para minimizar tais problemas, em 2009 a CAPES publicou duas portarias a 7/2009 e a 17/2009 em cujos textos estabelecem que a avaliação dos cursos de mestrado profissional devam ser realizadas com fichas de avaliação próprias e com sub-comissões específicas, preferencialmente constituídas por professores de mestrados profissionais. Tais portarias foram acompanhadas de uma ficha de avaliação publicada somente no final do triênio com algumas poucas modificações em relação à ficha dos cursos na modalidade acadêmica.

Em 2011 e 2012 em um esforço de democratização, foram realizadas reuniões dos coordenadores de mestrado profissional com a coordenação de área da CAPES com vistas à discussão da avaliação dessa modalidade de mestrado. Os documentos oriundos dessas reuniões encontram-se na página da área de Administração, Contabilidade e Turismo na Capes. O que se verifica a partir desses documentos é que, apesar da necessidade de diferenciação entre as modalidades acadêmica e profissional, muito se discute, mas pouco se avança, talvez pela falta de unanimidade acerca do assunto ou porque a comunidade acadêmica não sabe ainda como manter o rigor desses cursos e, ao mesmo tempo, romper com o modelo dominante que é o mestrado acadêmico.

Dentre os itens debatidos nas reuniões estava o controverso "qualis tecnológico", o qual demandou muitas horas de debate para ser decidido em poucos minutos, esforço este que não convenceu o Conselho Técnico-Científico - CTC da Capes. Como resultado, ao final de março de 2013, às vésperas da entrega do Coleta Capes, a nova ficha de avaliação com suas alterações ainda não havia sido divulgada.

$\mathrm{Na}$ atual gestão se observa uma abertura junto à coordenação de área da Capes para a discussão dos mestrados profissionais, denotando que muito ainda há que se discutir sobre a avaliação desses cursos, visto que tanto para os gestores desses programas quanto para a comunidade científica pontos obscuros ainda persistem. 
Tendo em vista tal necessidade a pesquisa que subsidia este artigo busca analisar o atual sistema de avaliação dos cursos de mestrado profissional na área de administração, contabilidade e turismo no Brasil, a partir dos próprios professores e coordenadores.

\section{O MESTRADO PROFISSIONAL}

Já na década de 80 se iniciaram as discussões acerca das dificuldades na construção de critérios de avaliação a serem aplicados na apreciação de propostas dos cursos de mestrado profissional. Em 1995 o documento intitulado "Capes: Metas da Atual Gestão" contém claras referências à necessidade de rever o modelo de pós-graduação do país cujo principal objetivo é a formação de quadros acadêmicos, e da necessidade de flexibilização da pós-graduação stricto sensu, particularmente o mestrado, com vistas ao atendimento de demandas não acadêmicas (BARROS; VALENTIM; MELO, 2005).

Assim, em 1995 é constituída uma Comissão responsável pelo documento "Mestrado no Brasil - A Situação e uma Nova Perspectiva", que originou uma proposta da Diretoria Colegiada ao Conselho Superior da Agência, com o título "Programa de Flexibilização do Modelo de Pós-Graduação Senso Estrito em Nível de Mestrado" que, por sua vez, resultou na Resolução nº1/95 publicada pela Portaria 47/95. Tais documentos apontam para a importância da implantação de programas de formação profissional e da necessária implantação pela CAPES de procedimentos para avaliar e acompanhar essa modalidade de mestrado no contexto da pós-graduação brasileira com o mesmo nível de qualidade alcançado até então (BARROS; VALENTIM; MELO, 2005).

Todavia os mestrados profissionais tiveram orientações mais específicas somente em 1998 pela Portaria 080 da CAPES que revogou a Portaria 47/95. A Portaria 080 caracteriza o mestrado profissional como título terminal. Barros, Valentim e Melo, (2005, p. 131) qualificam o mestrado profissional como "[...] a capacitação para a prática profissional transformadora por meio da incorporação do método científico".

A partir da publicação da Portaria 080, surgiram as primeiras experiências declaradas de mestrados profissionais incentivadas pelas demandas de empresas e agências que tinham como interesse a capacitação de profissionais no cenário da globalização (PIQUET, 2008). A implantação dessa modalidade de mestrado, todavia, gerou uma série de desconfortos e uma grande rejeição por parte da comunidade acadêmica. Antes mesmo de conhecê-los houve uma reação contrária em função do temor de que essa nova modalidade viesse a se contrapor ao 
desenvolvimento dos cursos acadêmicos pela redução de incentivos governamentais. Assim, tais cursos passaram a ser considerados cursos de "segunda linha" e uma ameaça aos títulos emitidos por mestrados acadêmicos (PIQUET, 2008).

De acordo com Ribeiro (2010) a rejeição inicial pode estar atrelada ao próprio crescimento do número de instituições privadas de ensino superior incentivado pelo governo. Para Ribeiro (2010, p. 436) “a transformação de um bem público, a educação, em mercadoria se deu no Brasil de maneira rápida e gerou uma série de problemas ainda hoje sem solução [...]". Outra razão destacada pelo autor é reflexo de uma disputa social nos moldes da "distinção" de Bourdieu (2000), de que mestres acadêmicos poderiam ter seus títulos desvalorizados em função do surgimento de uma nova e mais "fácil" modalidade de mestrado.

Com a persistência da rejeição, após 15 anos de existência há que se considerar uma questão social e histórica ainda mais antiga, ou seja, o afastamento da academia de seu contexto social mais amplo conforme destacado por Freire, "aparta do ensino a práxis" (RIBEIRO, 2010, p.437).

Mesmo após 15 anos desde sua aprovação, ainda persiste no meio acadêmico várias discussões, rejeições e indefinições em relação aos mestrados profissionais (TAKAHASHI, et al, 2010). Essas indefinições e rejeições expõem lacunas de pesquisa a respeito dos mestrados profissionais em diversos aspectos atrelados a ele e com as quais a presente pesquisa pretende colaborar, mais especificamente em relação à avaliação do mestrado profissional promovida pela Capes.

\section{AVALIAÇÃO: CONCEITOS E CARACTERÍSTICAS}

Avaliação pode ser compreendida como a análise sistemática e contínua de processos ou resultados de um determinado projeto, política ou programa, tendo como referenciais quesitos explícitos, a fim de cooperar para o seu aprimoramento e ajustá-lo aos critérios desejados pelo avaliador (RUA, 1998).

Weiss (1998) contribui para a discussão afirmando que avaliação é um termo elástico que se amolda para envolver ponderações de diversos tipos. Afirma ainda que o que todos os usuários desta expressão têm em comum é a ideia de julgamento de mérito e atribuição de valor. Quando um indivíduo examina algo, ele está observando um determinado fenômeno e comparando-o em relação a padrões implícitos ou explícitos pré-concebidos. Adicionalmente, Balthasar e Rieder (2000) reforçam que a avaliação é um processo de feedback que conecta os 
produtos, os resultados e os impactos de políticas e programas, com as estruturas de conhecimento que foram estabelecidas em seu planejamento ou formação.

Assim, o termo avaliação pode ser entendido como o ato de julgar e atribuir valor a um alvo específico, com base em padrões variados de valor previamente definidos e desejados como ideal para o item avaliado, podendo ou não seguir um padrão de retroalimentação contínua para o seu aprimoramento.

A avaliação possui várias adjetivações que foram incorporadas a sua utilização com o passar dos anos. É possível distinguir pelo menos cinco adjetivações: 1) ao tempo da avaliação; 2) à finalidade da avaliação; 3) ao objeto da avaliação; 4) a participação da avaliação e 5) ao impacto da avaliação (DIAS SOBRINHO, 2003).

É comum ocorrer uma repetição entre as adjetivações e suas categorias, visto que a taxonomia não pretende abstrair a essência da avaliação. Na adjetivação relacionada ao tempo de realização da avaliação, pode ser encontrada uma divisão de três tipos principais: a) A avaliação diagnóstica: é realizada no ponto zero, no início do processo com o objetivo de determinar o status do objeto em avaliação. Pretende favorecer a justaposição dos ideais planejados com a realidade avaliada; b) A avaliação de processo: ocorre durante a avaliação, e objetiva trazer informações sobre o andamento do processo para possíveis ajustes na rota e controle do desempenho; c) A avaliação de produto (ou de desempenho): é realizada no final do processo, e tem como missão verificar o alcance dos objetivos propostos no ponto zero. Também dentro da dimensão temporal, é possível encontrar a avaliação transversal, que é a observação de um recorte no tempo em determinado momento da avaliação longitudinal que coleta de dados ao longo de todo o processo.

$\mathrm{Na}$ dimensão voltada à finalidade da avaliação, pode-se revisitar os conceitos de Scriven (1967) que definiu a avaliação formativa e somativa. A primeira é efetivada no final do processo e investiga se as metas foram alcançadas e a segunda durante o processo e ambas visam aferir o desempenho. Quando o objeto da avaliação é analisado, é possível distinguir três tipos: 1) avaliação de produto, direcionada para o produto de um determinado processo; 2) avaliação de impacto, interessada em observar quais mudanças ocorreu no objeto avaliado entre o tempo zero e o tempo final da intervenção e 3) avaliação de efetividade, relacionada com a mensuração da realização de objetivos máximos de alcance social da ação avaliada.

Na dimensão relacionada ao modo de elaboração e implementação da avaliação Patton (1997) declara a existência da avaliação participativa, onde os stakeholders da avaliação 
ganham voz ativa durante o processo de avaliação e a avaliação emancipatória, que confere ao avaliado participação maior na análise da avaliação e possíveis ações futuras de correção.

Por fim, em relação ao impacto da avaliação sobre os avaliados, Dias Sobrinho (2003) insere às adjetivações high stakes e low stakes. A avaliação high stakes tem como característica principal o fato de influenciar o avaliado de forma direta durante e ao seu final do processo avaliativo com os resultados obtidos. Já a avaliação low stakes é quando a avaliação não tem o poder de influenciar a vivência do avaliado e, portanto não traz alteração ou ajuste. Todas essas adjetivações contribuem para um melhor entendimento das intenções dos stakeholders da avaliação.

Para Peterson (2000), existem três níveis de avaliação que podem suprir às necessidades de um grupo de stakeholders, tanto os internos quanto os externos. Esses três níveis de avaliação podem ser classificadas como: avaliação institucional externa; avaliação institucional por pares (peer review); e autoavaliação institucional.

Conforme Peterson (2000) a autoavaliação é aquela iniciada, dirigida e analisada pela própria IES para mensurar o alcance dos seus objetivos de qualidade. Mesmo promovida pela instituição, a IES pode solicitar a presença de analistas externos com especialidades na área ou mesmo outros representantes de organizações pares. O processo de auto-avaliação, quando bem conduzido, pode tornar-se um excelente instrumento para aumentar o envolvimento e participação dos stakeholders na instituição, criando uma atmosfera de evolução e melhoria, para que os objetivos institucionais sejam alcançados e as deficiências sejam corrigidas (SCHWARTZMAN, 1999).

Atualmente existe a tendência da utilização de modelos integrados de avaliação. As instituições de alto nível integram os três modelos de avaliação para maximizar o poder de evolução qualitativa da IES, mas Peterson (2000) salienta que este processo consome muito tempo e exige um número elevado de recursos, tornando essa integração algo vivenciado por poucas instituições no Brasil (PETERSON, 2000).

Os objetivos e finalidades da avaliação são os mais diversos possíveis. Estes estão condicionados a diversos interesses dos grupos avaliadores aos quais se reportam, tendo cada qual o seu modelo conceitual e expectativa em relação aos resultados da avaliação (AFONSO, 2000). Grande parte das avaliações possuem em sua iniciativa, uma gama variada de apoiadores, tanto internos quanto externos, que detém múltiplos interesses. Gerando múltiplas finalidades e propósitos (PETERSON, 2000). 


\section{MESTRADOS PROFISSIONAIS EM ADMINISTRAÇÃO, CONTABILIDADE E TURISMO NO BRASIL E SEU PROCESSO DE AVALIAÇÃO \\ DOI: http://dx.doi.org/10.5007/1983-4535.2014v7n1p298}

Para Dias Sobrinho e Ristoff (2002) a avaliação busca suprir alguns propósitos que se tornam comuns a muitos processos avaliativos. E conforme Kells (2000) os propósitos mais comuns são: evidenciar o accountability ou nível de comprometimento da IES em relação às cobranças e expectativas do governo; prestar contas à sociedade; comprovar a sua eficácia; demonstrar o alcance dos objetivos da instituição; oferecer confiabilidade em relação ao seu padrão de qualidade; tornar a IES elegível à financiamentos e recepção de recursos.

Outra finalidade relevante levantada por Belloni (2000) é a função social da avaliação, que pode ser entendida como a contribuição da avaliação para o desenvolvimento da democratização, do conhecimento e da educação. Essa função social corrobora com o aperfeiçoamento da qualidade da educação e com a formação profissional, resultando na transformação da sociedade.

Sobre a avaliação dos Mestrados Profissionais, Ribeiro (2005) enfoca que independente da modalidade do mestrado, acadêmico ou profissional, os dois são avaliados pela Capes com igual rigor, não tendo perda de qualidade em nenhuma das modalidades, necessitando apenas de melhor definição dos critérios e métodos de avaliação de cada proposta. Segundo Oller et al (2008), os parâmetros para avaliação do mestrado profissional, devem evoluir a cada avaliação trienal da Capes, para se ajustarem à identidade dos mestrados profissionais. É nesse sentido que esse trabalho busca oferecer contribuições.

Em julho de 2003 foi considerada pelo então Presidente da Capes a necessidade de uma discussão mais ampla sobre a natureza, a legalidade e a nomenclatura dos mestrados profissionais. Em face disso, foi proposto pela diretoria da agência um seminário nacional para prover o CTC e a diretoria da Capes de elementos adicionais com vistas a um consenso a respeito do assunto. Nesse momento, suspenderam-se as novas ofertas dessa modalidade de mestrado até a sua redefinição.

Em novembro do mesmo ano foi realizado o "Seminário sobre o Mestrado Profissional" com os membros do CTC, representantes de área da Capes, membros do Conselho Superior, representante do Fórum de Pró-Reitores de Pós-Graduação e coordenadores de MP convidados. A iniciativa, apesar de importante, novamente não produziu os efeitos esperados (BARROS; VALENTIM; MELO, 2005).

As avaliações que se seguiram 2001/2003, 2004/2006 e 2007/2009 continuaram a revelar os problemas já mencionados, permanecendo o modelo desenvolvido para os mestrados acadêmicos. Apenas na avaliação do último triênio 2007/2009 algumas pequenas 
alterações foram conduzidas, permanecendo, contudo, os parâmetros utilizados para os mestrados acadêmicos (CAPES, 2009). Soma-se a isto o fato da nova ficha de avaliação ser publicada somente no final do triênio, juntamente com a Portaria 17/2009.

Consciente da necessidade de novos critérios, a atual coordenação de área realizou em 2011 e 2012 reuniões com os coordenadores de mestrado profissional para discutir a avaliação dessa modalidade de mestrado, cuja ficha ainda não foi divulgada em finais de março de 2013. As discussões foram estabelecidas em cima da ficha de avaliação em curso, nos moldes do mestrado acadêmico, sem haver quebra de paradigma. $\mathrm{O}$ documento na íntegra encontra-se na página da área no sitio da Capes.

Todos esses fatos pressupõem que muito ainda há que se discutir sobre a avaliação desses cursos, visto que tanto para os coordenadores quanto para a própria Capes oportunidades de melhoria ainda parecem persistir, e que o trabalho, nesse sentido, apenas está sendo retomado

\section{PERCURSO METOdOLÓGICO}

Esta pesquisa caracteriza-se como sendo predominantemente quantitativa. A coleta de dados ocorreu por meio de um questionário on line a partir do aplicativo Surveymonkey enviado aos gestores e aos professores dos cursos de mestrado profissional na área de administração, contabilidade e turismo no Brasil. Ao todo foram enviados questionários à 465 professores, dentre os quais se incluem os coordenadores dos cursos.

O questionário foi planejado para coletar dados sobre a avaliação dos cursos de MP tendo em vista o atual sistema de avaliação dos mesmos pela CAPES. O questionário em seu primeiro bloco identifica a IES e suas principais características, assim como características dos respondentes. O segundo bloco engloba questionamentos acerca do atual sistema de avaliação dos MP pela Capes e o terceiro bloco se destina às críticas e sugestões sobre o mesmo.

Os 70 indivíduos que responderam à pesquisa consistem em coordenadores e professores dos cursos de mestrado profissional na área de administração, contabilidade e turismo no Brasil e representam $68 \%$ dos cursos de mestrado profissional e $50 \%$ dos coordenadores. Além disso, os respondentes representam todas as regiões do país, exceto a região norte, conforme descrito na apresentação dos dados. A amostra do estudo não é probabilística, mas oferece percepções importantes sobre o processo de avaliação dos MPs 
que, muitas vezes, não são externalizados em reuniões coletivas. O questionário foi respondido entre os meses de abril a agosto de 2012, logo após as reuniões em Brasília nas quais foram discutidas, pela maioria dos coordenadores presentes, as mudanças na ficha de avaliação dos mestrados profissionais.

Os dados foram processados com o auxílio do software Excel e SPSS onde foram testadas múltiplas possibilidades de análise. Neste artigo são apresentados os dados da análise descritiva, envolvendo freqüência absoluta, percentual e média, além da tabulação cruzada. As variáveis de controle foram a função dos respondentes (coordenador x professores) e a natureza (pública x privada) das IES.

\section{APRESENTAÇÃO DOS RESULTADOS}

Segundo dados disponibilizados pela Capes (2013), o mestrado profissional na área de administração, ciências contábeis e turismo, possui uma representatividade menor em relação ao número de mestrados acadêmicos, porém crescente. Atualmente existem 75 mestrados acadêmicos no Brasil e 50 mestrados profissionais nesta área. Considerando que o mestrado profissional é mais recente e que representa $40 \%$ do total de cursos na área, torna-se necessário reconhecer a sua importância e contribuição para a pós-graduação brasileira.

Especificamente na área de administração, ciências contábeis e turismo o mestrado profissional estava presente em 14 unidades federativas do Brasil na última trienal (20072009) subindo para 15 unidades federativas, e de 41 para 50 cursos em março de 2013. Hoje os cursos estão assim distribuídos: 2 no norte, 9 no nordeste, 2 no centro oeste, 29 no sudeste e 8 no sul. $\mathrm{O}$ aumento dos cursos nessa modalidade em $12 \%$ em 3 anos justifica a necessidade de discuti-lo e avançar em relação às características e à avaliação dessa modalidade de curso.

\subsection{CARACTERIZAÇÃO DOS RESPONDENTES}

Os participantes da pesquisa estão distribuídos nas regiões do país na proporção da presença de cursos na modalidade profissional. Quando se verifica a instituição de ensino em que o respondente pertence, observa-se que a maior parte, ou seja, 57,14 pertence à instituições da Região Sudeste do país. Os demais respondentes estão dispersos nas outras regiões do país (22,85\% no nordeste, $18,57 \%$ no sul e $1,43 \%$ no centro-oeste), com exceção da região norte, que não respondeu à pesquisa. Isto pode ser explicado pelo fato de a região sudeste ser a que mais possui cursos de mestrado profissional em administração, ciências 


\section{MESTRADOS PROFISSIONAIS EM ADMINISTRAÇÃO, CONTABILIDADE E TURISMO NO BRASIL E SEU PROCESSO DE AVALIAÇÃO \\ DOI: http://dx.doi.org/10.5007/1983-4535.2014v7n1p298}

contábeis e turismo. Ao mesmo tempo, a região norte possui apenas 02 cursos nessa modalidade.

Do total de professores que responderam à pesquisa, $11,43 \%$ possuem menos de 2 anos de experiência na pós-graduação stricto sensu acadêmica, 15,71\% de 2 a 4 anos, 8,57\% de 4 a 6 anos, 18,57\% de 6 a 8 anos, 7,14\% de 8 a 10, 11,43\% de 10 a 12 e 27,14 possui mais de 12 anos de experiência. A média dos respondentes é de 9,18 anos de experiência na pós-graduação stricto sensu acadêmica.

No que se refere ao tempo de experiência dos respondentes como docentes no mestrado profissional, 21,43\% possui menos de 2 anos de experiência, 31,43\% possui de 2 a 4 anos, $10,00 \%$ de 4 a 6 anos, $11,43 \%$ de 6 a 8 anos, $8,57 \%$ de 8 a 10, 7,14\% de 10 a 12 e 10,00\% possui mais de 12 anos de experiência. A média dos respondentes é de 5,12 anos de experiência no curso de mestrado profissional.

Com relação à natureza, pública ou privada, das instituições a que pertencem os indivíduos que responderam à pesquisa, os percentuais obtidos demonstram uma distribuição equitativa das respostas, sendo $55,71 \%$ formado por instituições públicas e $44,29 \%$ por instituições privadas.

\subsection{O SISTEMA DE AVALIAÇÃO CAPES DOS MESTRADOS PROFISSIONAIS EM} ADMINISTRAÇÃO, CIÊNCIAS CONTÁBEIS E TURISMO SEGUNDO OS PROFESSORES E OS COORDENADORES

Os dados apresentados na sequência referem-se às respostas aos questionários aplicados referentes à avaliação dos cursos e mestrado profissional na área de administração, contabilidade e turismo entre abril e agosto de 2012.

O gráfico 1 exibe as respostas relativas à opinião dos respondentes em relação à mudança de critérios na ficha de avaliação dos mestrados profissionais no meio do triênio.

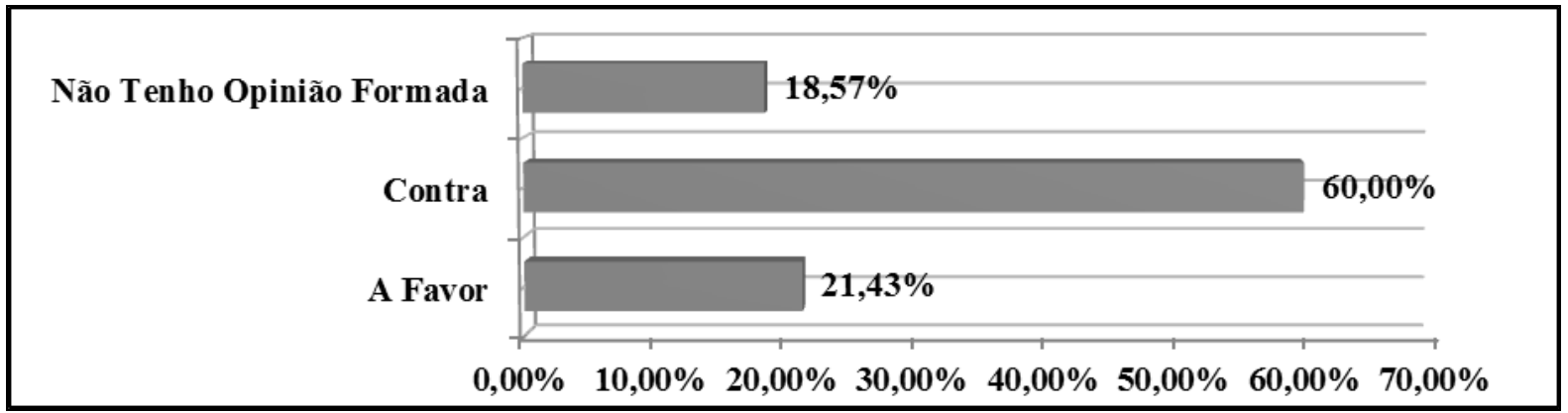

Gráfico 1 Mudança de Critérios no meio do triênio. 
Observa-se com base nas respostas que $60,00 \%$ dos respondentes se posicionaram contra esta decisão da Capes e apenas 21,43 \% manifestou-se a favor desta mudança. Do total, 18,57 \% não possui opinião formada sobre esta questão.

Nas perguntas abertas, a mudança das regras no meio do triênio ou a instabilidade das regras foi bastante citada como um problema no atual sistema de avaliação da Capes: "cobrar produção, mas não oferecer contrapartida para quem produz e, ainda, alterar as regras do jogo durante a partida não é justo".

Quando perguntados sobre a necessidade de exclusão de itens na ficha de avaliação dos mestrados profissionais, a maioria dos participantes da pesquisa, $65,71 \%$, respondeu que não vê esta necessidade, enquanto $34,29 \%$ dos respondentes consideram que existem itens que devem ser excluídos da ficha de avaliação do MPs.

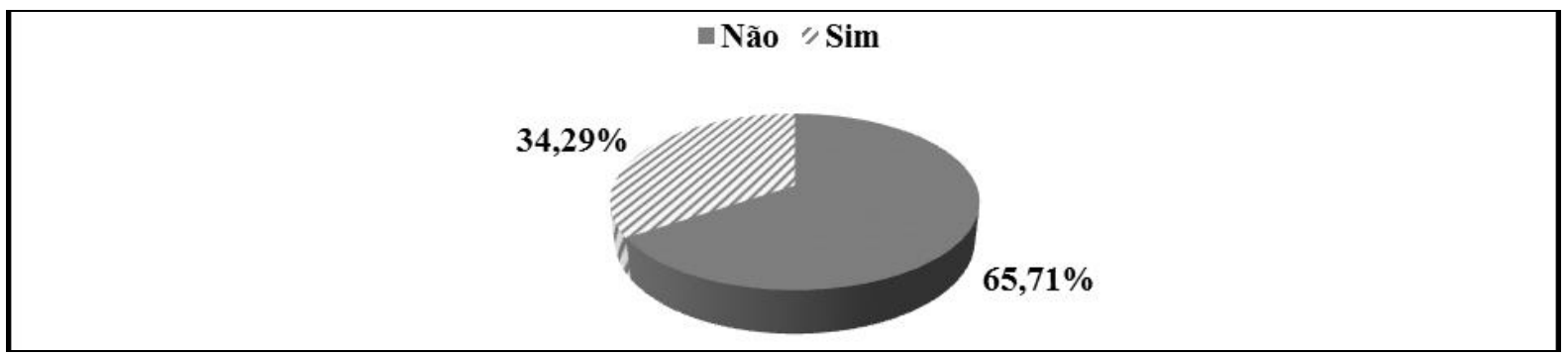

Gráfico 2 Exclusão de itens da atual ficha de avaliação.

Apesar de a maioria dos respondentes afirmarem que não há itens a serem excluídos da ficha de avaliação (Gráfico 2), 48,57\%, ou seja, quase a metade dos respondentes concorda que a CAPES não deve manter os atuais critérios de avaliação dos MPs em sua ficha vigente, apenas 15,71\% acham que a CAPES deve manter os atuais critérios, e 35,71\% dos entrevistados afirmaram não ter opinião formada sobre essa questão (Gráfico 3). Quando esta informação é analisada separadamente (tabulação cruzada), entre professores e coordenadores, o resultado não se modifica, ou seja, a maior parte continua achando que os critérios atuais devem ser modificados.

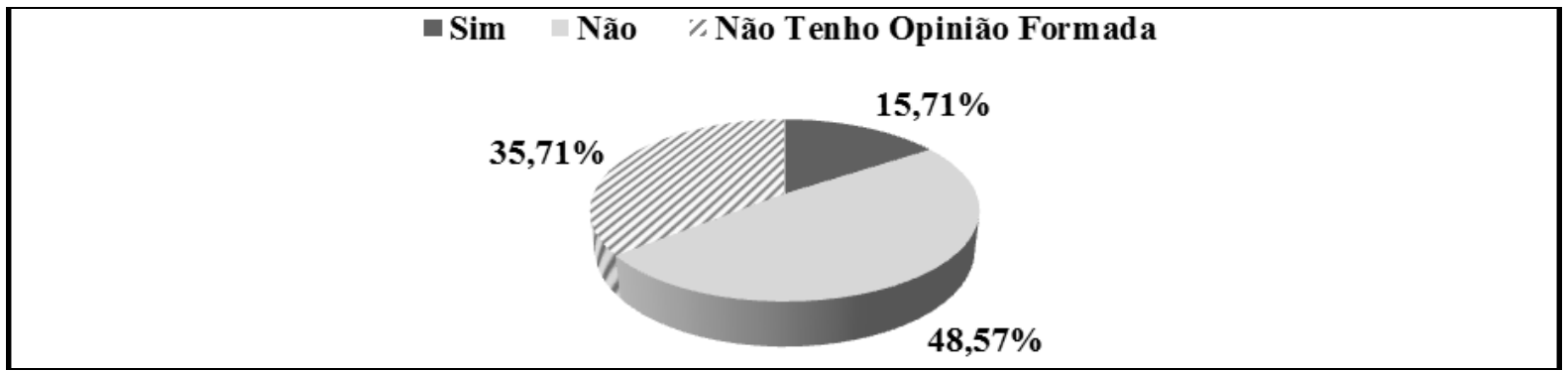

Gráfico 3 Manutenção dos atuais critérios de avaliação. 
A incongruência entre as respostas apresentadas nos gráficos 2 e 3 pode representar que, embora grande parte concorde que os critérios devam ser modificados, na prática não se sabe como proceder para que essa mudança seja empreendida. $\mathrm{Na}$ falta de critérios de avaliação, opta-se pela existência dos atuais. Outro argumento para essa dissonância pode ser reflexo do fato de que a grande maioria dos professores de MPs da área é oriunda de programas acadêmicos, tornando-se difícil a quebra de paradigmas. Aqueles que não têm opinião formada são, sobretudo, professores não coordenadores, o que respalda o fato de que o maior peso da responsabilidade sobre o conhecimento da avaliação dos cursos é depositada nos coordenadores.

Nas questões abertas sobre os problemas da avaliação corrente são citados a "falta de critérios específicos para os MP", assim como a "ausência de critérios que reflitam as peculiaridades dos mestrados profissionais, levando ao tratamento de modo igual de coisas diferentes".

Com o gráfico 4 observa-se que a maioria, $54,29 \%$ dos entrevistados, é a favor de que exista um "ranking" diferenciado para os mestrados profissionais, com conceitos e notas que sejam distintos dos utilizados nos mestrados e doutorados acadêmicos (3 a 7). Este tem sido um item bastante discutido e levantado como um dos problemas nas perguntas abertas, pois um ranking diferenciado evitaria a comparação e representaria uma forma de romper com o paradigma dominante, trazendo uma maior identidade a esses cursos.

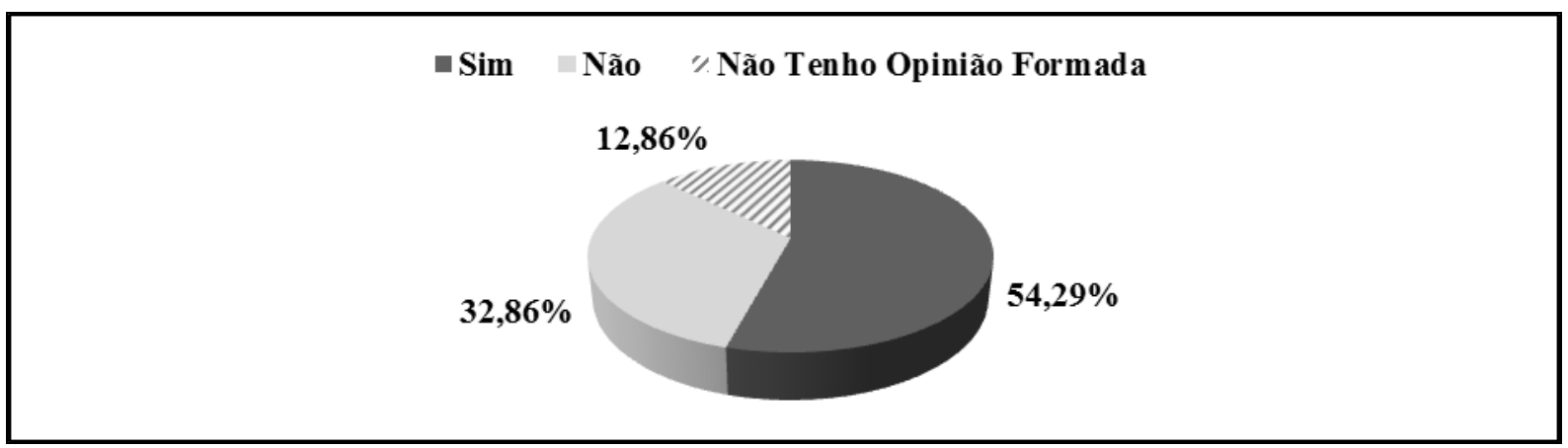

Gráfico 4 Criação de um ranking diferenciado para os mestrados profissionais.

O gráfico 5 mostra a opinião dos entrevistados quanto à periodicidade trienal de avaliação da CAPES. A grande maioria dos entrevistados, 75,71\%, julga a avaliação trienal adequada para verificar se o curso está atendendo às demandas de formação para o mercado de trabalho, com o rigor da proposta do stricto sensu. 


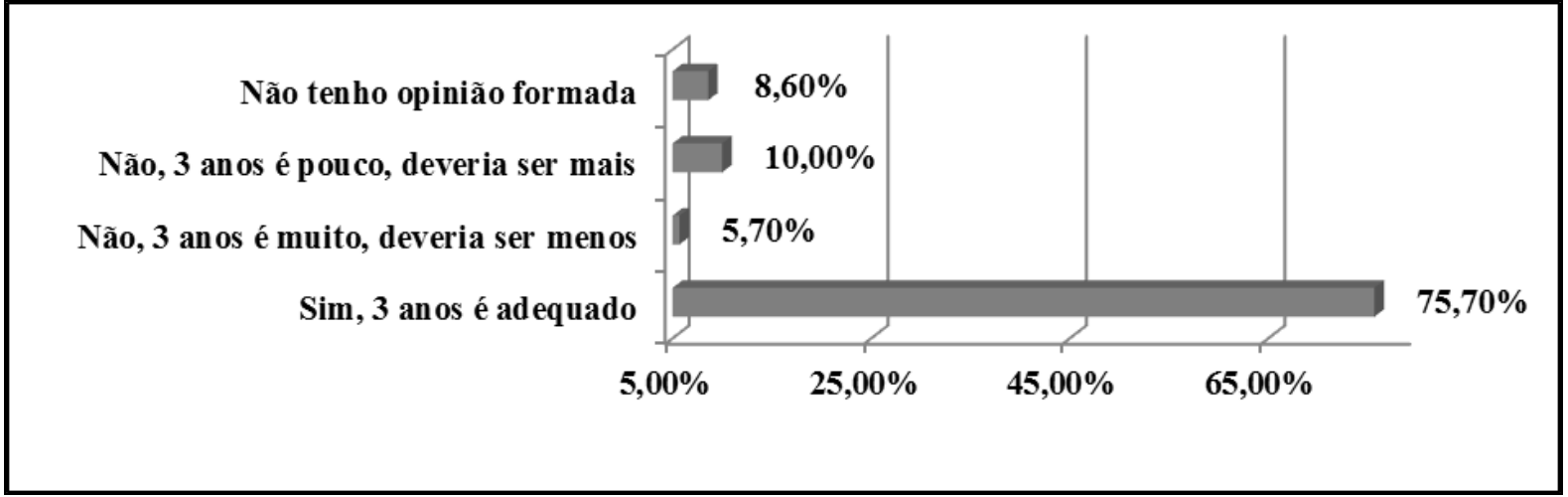

Gráfico 5 Periodicidade da avaliação dos mestrados profissionais.

No gráfico 6 observa-se que 54,29\%, ou seja, a maioria dos respondentes coloca-se a favor da inclusão de "profissionais de mercado" da área como integrante da comissão de avaliação da Capes para o mestrado profissional.

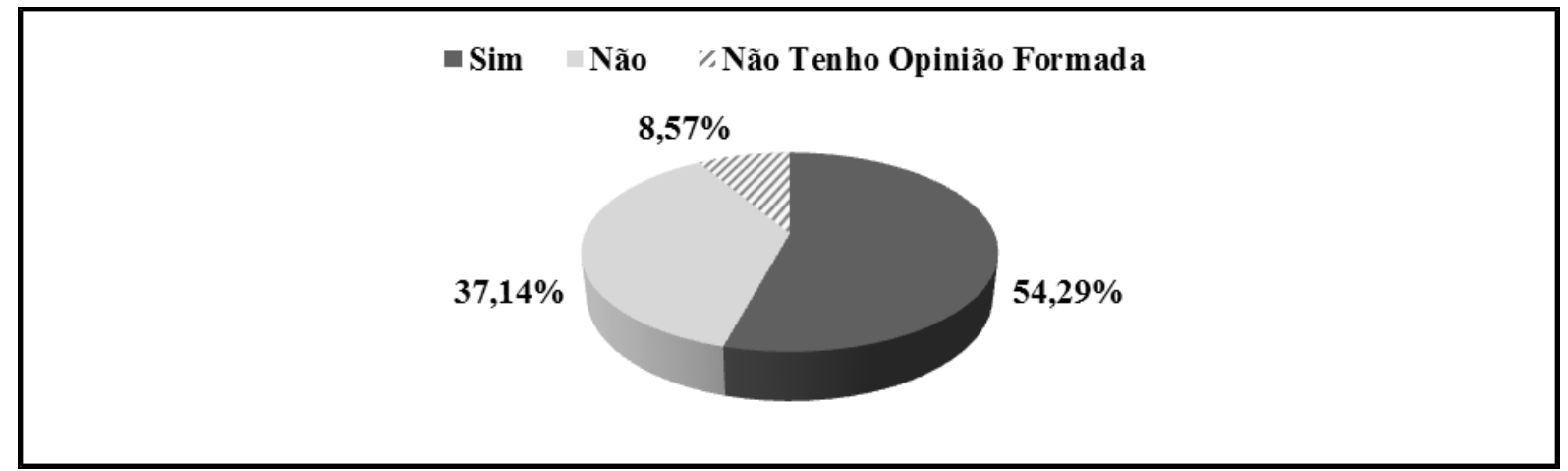

Gráfico 6 Inclusão de profissionais de mercado na Comissão de Avaliação dos Mestrados Profissionais.

Essa questão recai na tão falada identidade dos cursos na modalidade profissional também destacada nas perguntas abertas. Sobre essa questão afirmam alguns, "não se tem nenhuma noção de como distinguir mestrado profissional do acadêmico". E, "embora os itens em análise sejam compatíveis com um mestrado profissional, a forma como são avaliados não difere do mestrado acadêmico". Assim, "os avaliadores avaliam os MPs com a cabeça do acadêmico o que os faz olhar muitas das vezes com preconceito para o mestrado profissional". Outro ponto levantado a esse respeito está associado à "ausência de professores de MPs nas comissões de avaliação" até então, gerando uma "tendência a avaliar os MP como se fossem MA".

A grande maioria dos entrevistados, 81,43\%, também é favorável à inclusão dos mestrados profissionais na estrutura dos Programas de Pós Graduação stricto sensu. Essa 
informação pode ser observada no gráfico 7. O percentual de professores/coordenadores que concorda com a inclusão dos MPs na estrutura dos PPGs chama atenção, pricipalmente considernado que pode haver uma retroalimentação sadia entre esses cursos que já foi apontada outrora pela Capes como benéfico na ficha de avaliação dos mestrados acadêmicos.

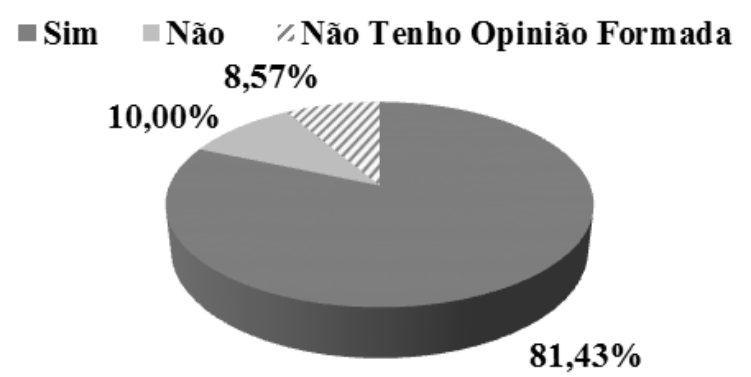

Gráfico 7 Inclusão dos MPs no PPG das IES.

Do total dos respondentes $72,86 \%$ consideram que a ficha de avaliação do mestrado profissional precisa de mudanças quando comparada à ficha do mestrado acadêmico, 7,41\% acredita que a ficha não necessita de alterações nesse sentido e $20 \%$ não têm opinião formada (Gráfico 8). Esse dado é curioso, na medida em que apenas 48,57\% não concordam com a manutenção dos atuais critérios de avaliação. Essa diferença percentual (24,29\%) pode estar atrelada ao alto percentual de respostas sem opinião formada (35,71\%) conforme demonstrado no gráfico 9. Ou seja, parece haver muito mais dúvidas em relação à manutenção dos atuais critérios de avaliação do que em relação à necessidade de diferenciar os mestrados profissionais dos acadêmicos.

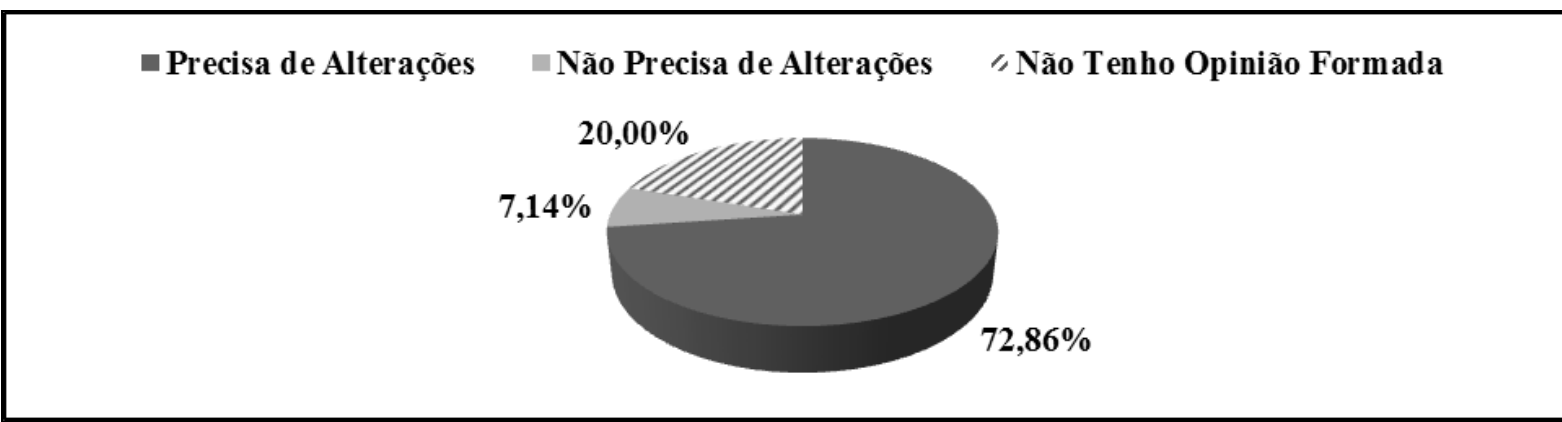

Gráfico 8 Alterações da Ficha de Avalição dos MPS em Relação a Ficha do MA.

Mesmo com a maioria dos respondentes considerando que a ficha de avaliação dos mestrados profissionais precisa de mudanças, 48,57\% dos entrevistados julga que o sistema de avaliação contribui para que os MPs obtenham melhorias na qualidade da formação 
profissional dos discentes (Gráfico 9). Do total, 25,71\% afirmam que não é possível mensurar a ocorrência desse fato e $25,71 \%$ não acreditam que o sistema de avaliação proporcione essas melhorias. Para quase metade dos entrevistados, apesar do sistema possuir falhas, ele cumpre com o seu papel.

- Sim $\square$ Não $/$ Não Tenho Opinião Formada

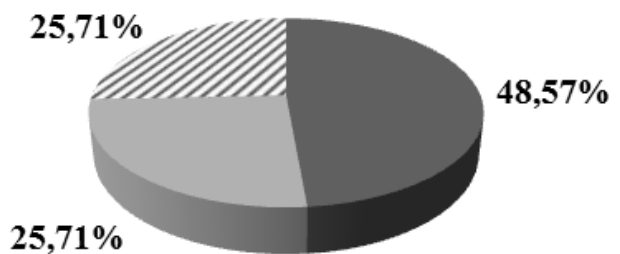

Gráfico 9 Contribuição do sistema de avaliação para obtenção de melhorias no curso.

No gráfico 10 percebe-se que a mais do que a maioria dos entrevistados, 52,86\% não utiliza outro instrumento interno de avaliação e acompanhamento para mensurar a qualidade do Mestrado Profissional e 47,14\% faz sim o uso de algum outro instrumento para a mensuração da qualidade do mestrado profissional.

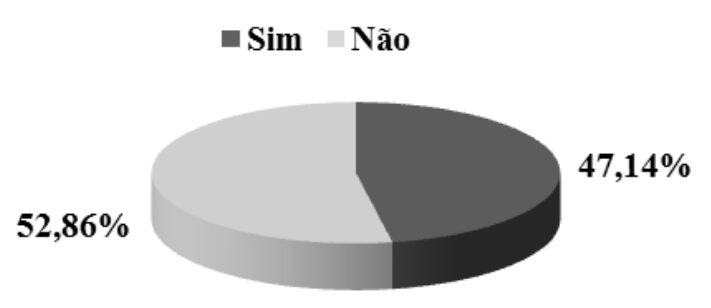

Gráfico 10 Utilização de outro sistema de avaliação além da avaliação CAPES.

Entretanto, quando se analisa esse dado entre as IES públicas e as IES privadas (Gráfico 11) o cenário se modifica, uma vez que das IES privadas $74,2 \%$ utilizam outro sistema de avaliação concomitantemente ao da Capes, ao passo que entre as públicas, apenas $25,6 \%$ o faz. Isso corrobora a tradicional dificuldade que as IES públicas têm de criar ou levar à cabo sistemas internos de avaliação. 


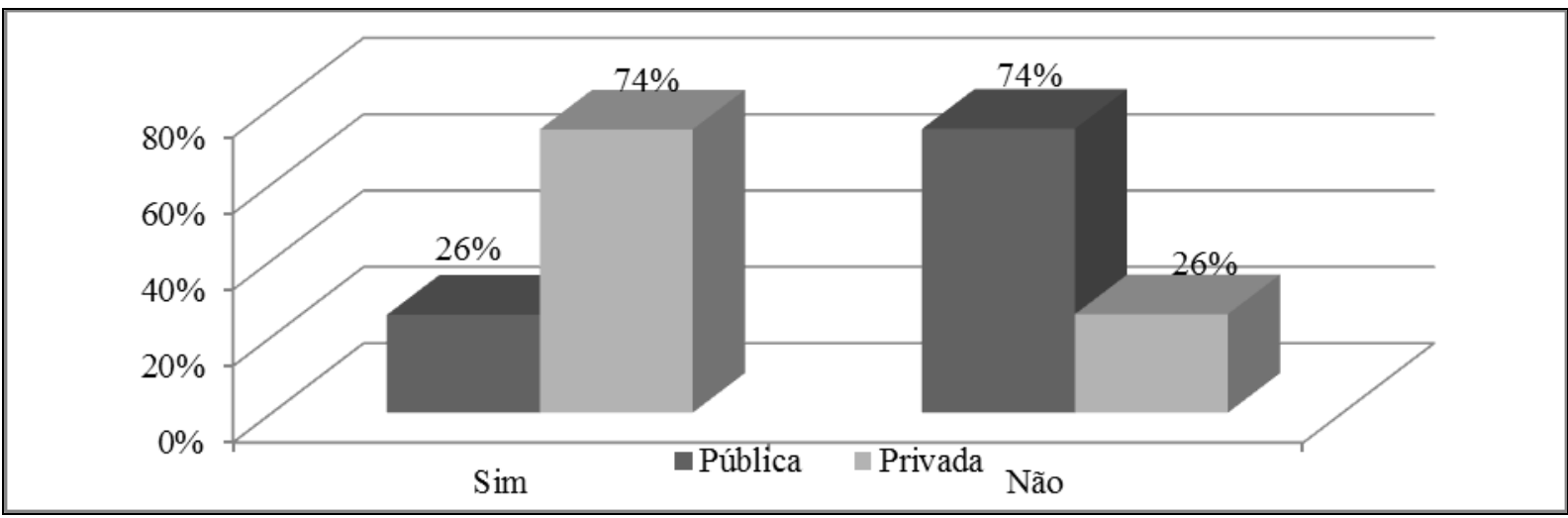

Gráfico 11 Utilização por IES públicas e privadas de outro sistema de avaliação.

Além das questões fechadas, a pesquisa também levantou junto aos professores e aos coordenadores os principais problemas percebidos na avaliação dos Mestrados Profissionais pela Capes. Os problemas levantados, de uma forma geral, referem-se à falta de uma política clara e objetiva do que se pretende, pois "aparentemente os Mestrados Profissionais visam suprir os MBA que fracassaram por falta de rigor acadêmico e proficiência de idioma". Ou à "falta de clareza sobre o que a realmente a Capes/MEC deseja com esses mestrados", ou ainda, "eles não sabem o que querem e, os avaliadores e policy makers estão vinculados a nichos de poder".

Sobre a questão MA x MP, alguns respondentes destacam a ideia de que existe uma "falta de clareza quanto às contribuições do mestrado acadêmico na área". Nesse sentido, argumentam: "os MPs surgiram como decorrência do afastamento dos MAs da realidade organizacional”. Entretanto, "a figura híbrida do MP - parte acadêmico, parte profissional dificulta a compreensão do seu lugar e alcance". Ou seja, nesse sentido, "o problema estaria no mestrado acadêmico, e não no mestrado profissional. Afinal, a Administração, a Contabilidade e o Turismo não são ciências aplicadas?”

Outro ponto importante levantado diz respeito à desconsideração do impacto profissional nos resultados, contrariando a proposta de criação de tal modalidade. Segundo alguns dos respondentes, "não foi enfrentado o dilema atuação acadêmica $\mathrm{x}$ atuação profissional". Houve "uma simples incorporação dos parâmetros utilizados na avaliação dos mestrados acadêmicos". Nesse sentido, "essa discussão ainda precisa ser aprofundada para gerar metodologia, instrumento e avaliadores próprios”. Soma-se a isso o destaque para a questão contextual como um aspecto importante a ser considerado na avaliação dos mestrados profissionais, uma vez que "avaliar o impacto do programa no contexto em que está inserido" 
passa a ser crucial nesta modalidade de mestrado. Relacionado a isto está a falta de avaliação da qualidade das dissertações produzidas pelos cursos, bem como sua aplicabilidade e contribuição.

O controverso "qualis tecnológico" foi outro objeto de destaque entre os respondentes da pesquisa. "O qualis tecnológico recentemente definido será um problema. Foi definido no final de uma reunião em poucos minutos sem uma discussão mais aprofundada". Os argumentos giram em torno das seguintes questões: como serão comprovadas muitas das produções técnicas? Uma simples declaração de uma consultoria basta? Quanto tempo demorará uma patente? Talvez nenhum assunto nesse metier seja tão unânime, ou seja, a necessidade de definição de critérios claros e objetivos para avaliação da produção técnica/tecnológica. O problema é que não se sabe como fazer. Atrelado a isto são relatadas a “falta de compreensão do caráter aplicado e da importância da produção técnica/ tecnológica na formação dos MPs".

Um ponto de destaque entre os integrantes de IES públicas refere-se ao fato de que as universidades públicas têm muita dificuldade para conduzirem produção técnica relevante. Dentro dessa perspectiva, sugerem que os trabalhos de conclusão de curso sejam considerados como itens relevantes de produção técnica. Adicionalmente, "no setor público se enfrenta o sucateamento, a proibição de se ter outras fontes de receita oriundas de consultoria das organizações demandantes, além da proibição de cobrar das pessoas jurídicas cursos in company".

Ainda relacionado ao qualis tecnológico aparece a exigência de produção técnica dos professores. Sobre esse assunto, alguns argumentam: "não é justa a exigência de pontuação técnica para todos". E complementam: "o mestrado também deve valorizar professores acadêmicos. Para esses, não é justo exigir produção técnica. Esta deve ser deixada para o percentual de professores (com titulação) não acadêmicos". Outra crítica recai sobre a tendência da Capes em separar o corpo docente dos programas stricto sensu: "os mestrados profissionais devem utilizar seus professores dos programas acadêmicos e, simultaneamente, diversificar seu corpo docente com profissionais com destacada atuação profissional".

Outros aspectos destacados dizem respeito ao peso dos critérios de avaliação, à imposição de critérios que tomam cada vez mais tempo do pesquisador com a burocracia, a "inflexibilidade da CAPES em rever o instrumento e os critérios de avaliação dos MPs", a dificuldade de medir alguns itens avaliados, os percentuais ou pesos atribuídos a cada item, a 
permanência de indicadores de avaliação/mensuração não adequados para as Ciências Sociais, o viés mercadológico embutido nos indicadores de avaliação/mensuração, o afastamento do compromisso do mestrado com a ciência, a ausência de divulgação e esclarecimento em relação a esta modalidade de mestrado e a falta de clareza na ficha de avaliação. Muitas das críticas também recaem na questão do produtivismo, instituído pela "tirania da pontuação", sendo exigido para ambas as modalidades "o mesmo nível de publicações".

Por fim, vale destacar o depoimento de um respondente: "atualmente arrume a casa que vamos receber a visita, passa-se uma maquiagem, um perfume e tudo fica bonito", argumentando que as avaliações deveriam acontecer em momentos distintos, sem prévio aviso, a partir de um processo estruturado.

\section{CONCLUSÕES E CONTRIBUIÇÕES}

Este trabalho objetivou analisar o atual sistema de avaliação dos cursos de mestrado profissional na área de administração, contabilidade e turismo no Brasil, a partir dos próprios professores e coordenadores. Esta é uma demanda bastante atual, não somente pela necessidade de voltar a discutir os mestrados profissionais, mas pela obrigação imprescindível e cada vez maior de aproximação da produção do conhecimento gerado na Universidade com as empresas, o governo e as organizações sociais.

Spink (1997) chama a atenção para as emoções que afloram quando se utiliza a palavra "profissional" para caracterizar um mestrado. Os mestrados na interpretação do autor são "produtos de uma lógica institucional própria num sistema quase-fechado", sendo “inevitável que a sua repentina adoção em outros espaços de forma mais abrangente afetará os mecanismos de reprodução vigentes", especialmente se for considerado "um mundo onde a distinção entre teoria e prática não somente existe, mas, pior, é revestida com significados de superioridade". Para o autor, "a luta [...] para o direito a uma prática profissional reflexiva, é também a luta para uma prática acadêmica transformadora, no campo empresarial, nas agências públicas, nas entidades não-formais e nas múltiplas organizações da sociedade civil" (p. 164). É essa prática transformadora que deveria ser refletida no processo de avaliação dos MPs.

O presente trabalho mostrou que embora a avaliação dos MPs seja altamente high stakes, diagnóstica, de processo, de desempenho e de produto (DIAS SOBRINHO, 2003), 
seus objetivos parecem não ter sido alcançados em sua totalidade se considerado a avaliação de seu produto, de seu impacto e da sua efetividade (SCRIVEN, 1967).

Talvez a saída seja que, na dimensão relacionada ao modo de elaboração e implementação, a avaliação deva ser mais participativa, de forma a tornar o seu processo mais próximo da prática, refletindo de uma forma mais apropriada as características dos Mestrados Profissionais. Entretanto, parece que a academia brasileira ainda não possui respostas para essa questão. Romper com o paradigma dominante também se torna difícil quando, num processo paradoxal, aqueles que fazem parte do "campo" (BOURDIEU, 2000) lutam pelo domínio de seus códigos e de suas regras internas criando um campo de forças onde cada subgrupo busca manter sua posição dando origem a um processo autofágico.

Apesar do impasse, o artigo contribui com reflexões e sugestões importantes acerca do processo de avaliação dos mestrados profissionais a partir da ótica de professores e coordenadores desses cursos. Tomadas as devidas precauções, o artigo pode ser utilizado para a análise de outras áreas do conhecimento que desenvolvem mestrados profissionais.

\section{AGRADECIMENTOS:}

O presente trabalho foi realizado com apoio do $\mathrm{CNPq}$, Conselho Nacional de Desenvolvimento Científico e Tecnológico - Brasil, para quem os autores agradecem.

\section{REFERÊNCIAS}

AFONSO, A. J. Avaliação educacional: regulação e emancipação para uma sociologia das políticas avaliativas contemporâneas. São Paulo: Cortez, 2000.

AGOPYAN, V.; LOBO, R. O futuro do Mestrado Profissional. Revista Brasileira de PósGraduação, v. 4, n. 8, p. 293-302, Dezembro 2007.

BALTHASAR, A.; RIEDER, S. Learning from Evaluation: Effects of the Evaluation on the Swiss Energy 2000 Programme. Evaluation, v. 6, n. 3, p. 245-260, Jul 2000.

BARROS, E. C. D.; VALENTIM, M. C.; MELO, M. A. A. O debate sobre o mestrado profissional na Capes: trajetória e definições. Revista Brasileira de Pós-Graduação, v. 2, n. 4, p. 124-138, Jul 2005.

BELLONI, I.; MAGALHÃES, H.; SOUSA, L. C. D. Metodologia de avaliação em políticas públicas. São Paulo: Cortez, 2000.

BOURDIEU, P. Les structures sociales de l’économie. Paris: Seuil, 2000. 
BRASIL. MEC/CESu/CFE, de 3 de dezembro de 1965.

Lei $\mathrm{n}^{\circ} 11.502$, de 11 de julho de 2007. Diário Oficial da República Federativa do Brasil, Brasília, DF, 12 jul. 2007. Seção 1, p. 5. Disponível em: http://www.capes.gov.br/images/stories/download/legislacao/Lei11502_PresidenciaRe publica.pdf. Acesso em 05 de janeiro de 2012.

BUARQUE, C. A universidade numa encruzilhada. Confererência Mundial de Educação Superior + 5. BRASIL, M. D. E. D. Brasil: UNESCO. 1: 23-25 p. 2003.

CAPES. Portaria nº 080, de 16 de dezembro de 1998. Diário Oficial da República Federativa do Brasil, Brasília, DF, 11 jan. 1999. Seção 1, p. 14. Disponível em: http://www.capes.gov.br/ export/sites/capes/download/legislacao/Portaria_CAPES_080_1998. doc. Acesso em: 8 mar. 2011.

Portaria $\mathrm{n}^{\circ}$ 7, de 22/06/09 Diário Oficial da República Federativa do Brasil, Brasília, DF, 23 jun. 2009. Seção 01, p. 31. Disponível em: http://www.capes.gov.br/ export/sites/capes/download/legislacao/Portaria_CAPES_07_2009. doc. Acesso em: 8 mar. 2011.

Portaria $\mathrm{n}^{\mathbf{0}}$ 17, de 28 de dezembro de 2009. Diário Oficial da República

Federativa do Brasil, Brasília, DF, 29 dez. 2009. Seção 1, p. 20. Disponível em: http://www.capes.gov.br/ export/sites/capes/download/legislacao/Portaria_CAPES_17_2009. doc. Acesso em: 8 mar. 2011.

Relação de cursos Recomendados e Reconhecidos. Disponível em:

http://conteudoweb.capes.gov.br/conteudoweb/ProjetoRelacaoCursosServlet?acao=pesquisarI es \&codigoArea $=60200006 \&$ descricaoArea $=$ CI\%CANCIAS+SOCIAIS+APLICADAS+\&des cricaoAreaConhecimento $=$ ADMINISTRA $\% \mathrm{C} 7 \% \mathrm{C} 3 \mathrm{O} \&$ descricaoAreaAvaliacao $=\mathrm{ADMINIST}$ $\mathrm{RA} \% \mathrm{C} 7 \% \mathrm{C} 3 \mathrm{O} \% 2 \mathrm{C}+\mathrm{CI} \% \mathrm{CANCIAS+CONT} \% \mathrm{C} 1 \mathrm{BEIS}+\mathrm{E}+\mathrm{TURISMO}$ Acesso em $05 \mathrm{de}$ janeiro de 2013.

Documentos de Área: Administração, contabilidade e turismo. Disponível em:http://www.capes.gov.br/images/stories/download/avaliacao/ADMIN17jun10.pdf. Acesso em 05 de janeiro de 2012.

CASTRO, C. D. M. A hora do mestrado profissional. Revista Brasileira de Pós-Graduação, v. 2, n. 4, p. 16-23, Julho 2005.

CATANI, A. M.; OLIVEIRA, J. F. de; DOURADO, L. F. A política de avaliação da educação superior no Brasil em questão. In: DIAS SOBRINHO, José; RISTOFF, Dilvo I. (Org.). Avaliação democrática: para uma universidade cidadã. Florianópolis: Insular, 2002. p. 99-108.

DIAS SOBRINHO, J. D. Qualidade, avaliação: do Sinaes a índices. Avaliação, v. 13, n. 3, p. 817-825, Novembro 2008. 
Avaliação e transformações da educação superior brasileira (1995-2009): do provão ao sinaes. Avaliação, v. 15, n. 1, p. 195-224, Março 2010.

DIAS SOBRINHO, José . Avaliação da Educação Superior: regulação e emancipação. In:

; RISTOFF, Dilvo I. (Org.). Avaliação e compromisso público: a educação superior em debate. 2003. Florianópolis: Insular,

; RISTOFF, Dilvo I. (Org.). Avaliação democrática: para uma universidade cidadã. Florianópolis: Insular, 2002.

DURHAM, E. R. Avaliação. In: STEINER, J. E. e MALNIC, G. (Ed.). Ensino Superior: conceito e dinâmica. São Paulo: EDUSP, 2006.

FERREIRA, A. Uma análise das dimensões da qualidade de serviços em educação superior para o estabelecimento de cursos de pós-graduação. 2005. 142 p. Dissertação (Mestrado). Mestrado Profissionalizante em Engenharia, Universidade Federal do Rio Grande do Sul UFGRS, Porto Alegre.

FISCHER, T. Mestrado profissional como prática acadêmica. Revista Brasileira de PósGraduação, v. 2, n. 4, p. 24-29, Julho 2005.

Seduções e riscos: a experiência do mestrado profissional. Revista de Administração de Empresas, v. 43, n. 2, p. 119-123, Abr/Mai/Jun 2009.

Tréplica - Reimaginar a Pós-Graduação: Resgatando o Elo Perdido. Revista de Administração Contemporânea, v. 14, n. 2, p. 372-376, Mar/Abr 2010.

Documento - Sobre maestria, profissionalização e artesanato intelectual.

Documentos e Debates. Revista de Administração Contemporânea, v. 14, n. 2, 2010.

FOPROF - Fórum Nacional dos Mestrados Profissionais. Disponível em: http://www.foprof.org.br/documentos/. Acesso em: 8 mar. 2011.

HOUSE, E. R. Tendencias em evaluación. Revista de Educacion, n. 299, 1992.

KELLS, H. R. Conduzindo processos de auto-avaliação. In: SOUSA, E. C. B. M. D. (Ed.). Avaliação Institucional: leituras complementares. Brasilia: Universidade de Brasília, IESB, 2000.

MELO, K. V. A. Origem e institucionalização da pós-graduação strictu sensu profissional: um estudo de caso. 2002. Dissertação (Mestrado). Programa de Pós-Graduação em Administração, Universidade Federal de Pernambuco - UFPE, Recife.

MENANDRO, P. R. M. Réplica 2 - Mestrado Profissional, Você Sabe Com Quem Está Falando? Revista de Administração Contemporânea, v. 14, n. 2, p. 367-371, Mar/Abr 2010 . 
NEGRET, F. A identidade e a importância dos mestrados profissionais no Brasil e algumas considerações para a sua avaliação. Revista Brasileira de Pós-Graduação, v. 5, n. 10, p. 217-225, Dez 2008.

NEVO, D. Conceptualization of education evaluation: an anlytical review of literature. In: SCRIVEN, M. (Ed.). Evaluation thesaurus. Newbury Park, CA: Sage, 1991.

OLLER, C. et al. Parâmetros para avaliação de mestrado profissional. Revista Brasileira de Pós-Graduação, v. 2, n. 4, p. 151-155, Jul 2008.

PAIXÃO, R. B.; BECKER, J. L. Indicadores de Impacto de Mestrados Profissionais: construção e análise à luz da multidimensionalidade. Encontro Nacional dos Programas de Pós-Graduação e Pesquisa em Administração. Rio de Janeiro. Anais. Anpad, 2012.

PATTON, M. Q. Utilization-ocuse evaluation. Newbury Park: Sage Publications, 1997.

PETERSON, M. Avaliação institucional na educação de nível superior. In: SOUSA, E. e MACHADO, C. B. D. (Ed.). Avaliação Institucional. Brasília: Universidade de Brasília IESB, 2000.

PIQUET, R.; LEAL, J. A. A.; TERRA, D. C. T. Mestrado profissional: proposta polêmica no Sistema Brasileiro de Pós-Graduação - o caso do planejamento regional e urbano. Revista Brasileira de Pós-Graduação, v. 2, n. 4, p. 30-37, Jul 2008.

PIQUET, R. Mestrado profissionalizante: relato de uma experiência. Regiões e Cidades, v.1, n.1, 2008, p. 2-9.

QUELHAS, O. L. G.; FILHO, J. R. F.; FRANÇA, S. L. B. O mestrado profissional no contexto do sistema de pós-graduação brasileiro. Revista Brasileira de Pós-Graduação, v. 2, n. 4, p. 97-104, Jul 2005.

RIBEIRO, C. R. A universidade como disputa da reprodução social: contribuição ao debate sobre os mestrados profissionais. Revista Brasileira de Pós-Graduação, v. 7, n. 14, p. 433450, Dez 2010.

RIBEIRO, R. J. O mestrado profissional na política atual da Capes. Revista Brasileira de Pós-Graduação, v. 2, n. 4, p. 8-15, Jul 2005.

RISTOFF, D. I. Algumas definições sobre avaliação. Avaliação - Revista da Rede de Avaliação Institucional da Educação Superior, v. 8, n. 1, p. 19-30, Mar 2003.

RUA, M. D. G. Análise das Políticas Públicas: Conceitos básico. Mimeo, 1998.

RUAS, R. Mestrado modalidade profissional: em busca da identidade. Revista de Administração de Empresas, v. 43, n. 2, p. 55-63, Abr/Jun 2003.

SCHWARTZMAN, S. O contexto institucional e político da avaliação do ensino superior. São Paulo: NUPES, 1990. 
Modelo para avaliação de desempenho: uma aplicação à atividade de extensão universitária. Tese de Doutorado apresentada à FEA/USP. São Paulo, 1999.

SCRIVEN, M. The Methodology of evaluation in perpectives of curriculum evaluation: aerea monograph series on curriculum evaluation. Chicago: Rand McNally, 1967.

SOUSA, E. C. B. M. D. Avaliações em instituições de ensino superior. Brasília: Universidade de Brasília, IESB, 1999.

TAKAHASHI, A. R. W. et al. Mestrado profissional e mestrado acadêmico em administração: convergências, divergências e desafios aos programas de pós-graduação stricto sensu no Brasil. Administração: Ensino e Pesquisa, v. 11, n. 4, p. 551-578, Out/Dez 2010.

VASCONCELOS, F. C. D.; VASCONCELOS, I. F. G. D. Réplica 1 - As Dimensões e Desafios do Mestrado Profissional. Revista de Administração Contemporânea, v. 14, n. 2, p. 360-366, Mar/Abr 2010.

VOLPI, M. T. A universidade e sua responsabilidade social. Porto Alegre: EDIPUCRS, 1996.

WEISS, C. H. Evaluation: Methods for Studying Programs and Polices. Upper Saddle River, NJ: Prentice Hall, 1998.

WILLIS, D. Educational assessment and accountability: a New Zealand case study. Jornal of Education Policy, v. 7, n. 2, 1992.

WOOD, T. J. R.; PAULA, A. O Fenômeno dos MPAs Brasileiros. Revista de Administração de Empresas, v. 44, n. 1, p. 116-129, 2004. 